\title{
Culture Repackaged:
}

\section{An Ethnography of the Globalized Sub-Culture of Tabletop Wargamers}

\author{
Rainier Lee
}

The purpose of this research is to show the changing face of cultural participation in hidden subcultures of the West. Through repackaging social partnership to adapt to post-modern realities, Middle-Earth Strategy Battle Gamers establish community, identity, and social mobilization through tabletop wargaming. This research is a call for anthropologists to expand their presence on social media as a means of understanding shifting images of culture. It is also a call for Christian participation in all segments of society.

Culture is constantly being formed and developed. Societies traditionally located in one geographical location now disperse across the globe. Migration, technological advancements, and access to entertainment have created a sense of cultural loss. Middleclass Westerners demonstrate this reality through modernized lifestyles that disassociate with ancestral religion and social representation. My research, however, challenges the notion of cultural loss in the West. This ethnography will illustrate through tabletop wargaming communities how hidden cultures establish new formations of artistic expression. Through the process, Western culture is reproduced within a globalized context.

This article reflects thirteen months of ethnographic data collection on a network of people who play, collect, and participate in a recreational hobby entitled, "The Middle-Earth Strategy Battle Game" (MESBG). My investigation followed current players and collectors of the MESBG. There has been social scientific research to date on video games and electronic social exchange. Tabletop wargaming, however, has not been studied significantly in anthropology.

The scope of my ethnographic research includes the global consumer sub-culture that manifests through buying, painting, modeling, and playing the MiddleEarth Strategy Battle Game. My questions and themes demonstrate aspects of a post-modern globalist world dominated by consumerism. Notions of transnational cultural formations will also be in evidence as I highlight social media's importance in current Western communal practices.
The research results will be viewed through the following anthropologists' theoretical frameworks: Marcel Mauss' obligatory system of exchange (2015), Arjun Appadurai's concept of social neighborhoods (1996), and Edward Said's contextualization of imagined space (2006). Edith and Victor Turner's understanding of pilgrimage will also be used to analyze and understand tabletop wargamers beliefs and behavior (2011).

My argument here is that Western societies repackage cultural participation as a means of adaptation to post-modern realities. Through the activities of tabletop wargamers we can see that culture evolves within the ever-changing face of social participation. Additionally, viewing the matter theologically, we can see a parallel with humanity seeking purpose through communal fellowship. Finally, it is worth noting that both Christianity and anthropology have a call to narrate the lives of the underrepresented, something I endeavor to do here.

\section{Methodology}

For my data collection, I used standard ethnographic tools, such as interviewing wargamers, engaging in tournaments through participant-observation, and establishing myself as part of multiple MESBG associations. Middle-Earth Strategy Battle Gamers form networks through social media. There is a connection here to Arjun Appadurai's concept of the social imaginary (1996). The MESBG association is based on imagined worlds (taken from Tolkien and 
Games Workshop), affiliates globally, and includes social hierarchies, group affiliation, and collective formation through social media.

There are three primary avenues of data collection revealing three different arenas within which the culture operates. The first avenue is the social media and online formats through which the MESBG community stays engaged with their hobby by way of imagined spaces. The second is casual gaming among players taking place in stores in Eastern Pennsylvania. This avenue demonstrates how local gamers mobilize, creating social neighborhoods which connect to both the immediate game being played and to the greater international association. The third and final avenue of data collection is attendance at MESBG tournaments. This branch of study demonstrates how many players travel long distances, both regional and internationally to celebrate their hobby. In sum, I will describe how through imagined spaces on Facebook and YouTube players mobilize by way of their local social neighborhoods to travel long distances to attend their games.

Although the MESBG community is globalized, my primary focus of ethnographic data collection and informant interviewing was in the American scene, specifically the eastern portion of the United States. Still, through social media and travel to games, this regional phenomenon is intimately connected with the global phenomenon of tabletop war gaming and demonstrates something of the growing importance of social media in both mobilization and representation.

\section{An Image of Middle-Earth Strategy Battle Gamers Through the Lens of Ethnographic Narration}

Countless muffled conversations, and lighthearted yelling. Dice hitting elegant $4 \mathrm{x} 4 \mathrm{ft}$. scenic tables mirroring Peter Jackson's cinematic Lord of the Rings trilogy accompanied by the aroma of approximately three hundred participants cramped into a hotel conference room. These are the sights and smells of Nova Open, the largest annual tabletop wargaming convention in North America, located in Washington D.C, which proudly boasted over 2,000 attendees in 2017. Situated within the many gaming systems at Nova are a small group of approximately 65 individuals (dominantly male), who represent various states and provinces in North America as well as nations across the Atlantic Ocean. These members constitute an active group of the global community who play and collect the MiddleEarth Strategy Battle Game.

A convention of Middle-Earth Strategy Battle Game enthusiasts looks like a simple Western sub-cultural gaming tournament. Although this image is correct, there are also hidden social meanings and realities that reflect themselves through the games, including artistic identity, the formation of community, a link to consumerism, and the global connection. Some of these hidden meanings were revealed after a long day of gaming at a 30 person sized panel at Nova Open. The group was in a small conference room that was arranged by Games Workshop's MESBG developmental head Adam Troke, who discussed the future of the game.

Troke encouraged his audience by telling them that it was their backing for the game that gave rise to a current revival of miniature manufacturing and company support. With a deep-voiced English accent that fit his large frame, Troke spoke about a release "schedule" (shed-yool) of new models and updated rules to come out next year. Upon hearing this, a young male wearing a custom printed shirt titled Carolinas' Middle Earth League, with a strong American Southern accent whispered to his friend, "schedule, what the hell is a schedule," to which his friend replied, "schedule (sched-yool) is British for schedule (skedzh-ool).”

The panel then opened itself to questions as a middle-aged man conveyed concerns that his local Warhammer store does not stock-up on or advertise MESBG models, and as a result Vancouver (Canada) based players do not have an outlet for new members. Following that, a soft accented Ontario member stated that he himself "cares about (aboot)" new players, but Games Workshop needs to express that they do as well. Similar sentiments were repeated by many American players who represented the greater Northern Virginia /Southern Maryland regional group called the DCHL (District of Columbia Hobbit League). Troke calmed these fears as he gave hints of change to come and alluded to new miniature releases which had not appeared in over a year.

After Troke's presentation on the future of the game, a pepper-haired man who represented the GBHL (Great British Hobbit League) spoke to the panel with an Irish slang about strategy and army list building as he hyped-up this modest-sized global group for the five-game Grand Tournament that was to come over the next two days. The speeches reminded me of General Dwight D. Eisenhower's speech to the Allied forces before they set out to liberate Europe from Nazi tyranny:

You are about to embark on a Great Crusade, toward which we have striven these many months. The eyes of the world are upon you . . . in company with our brave Allies and brothers-in-arms. (Eisenhower 1944)

Eisenhower's words would have fit well with the spectacle I was witnessing. Western participants from all walks of life brought together by a common interest had 'embarked' on a modernized social pilgrimage across state and national borders. With their 
miniatures, dice, and tape measures they were ready for war. The social performance I observed of Irish, English, Canadian, and American individuals represented an integrated network of a Western subculture that put energy, finances, and planning into attending what constituted a ceremonial commencement of the tournament. It mirrored the individual conversations I had with a Tennessean, Arkansan, and Quebecois who had traveled to Washington D.C. alone to engage in their passion of playing the MESBG.

\section{Online Community}

There are three primary stages in the process of establishing oneself in the MESBG sub-culture and its imagined space of affiliation. These stages are: interest, participation, and establishment. In the first stage, interest, YouTube is critical. YouTube is where individuals are drawn through visual stimulation towards an interest in Game Workshop's Middle-Earth tabletop game. Participation is the second stage. In this stage, individuals install or become part of Facebook groups associated with their local region, or country of habitation. Establishment as an active gamer is the last stage of entering the MESBG sub-culture. Through Facebook, the participation in the hobby becomes an established practice as individuals meet to interact with one another for regular gaming.

\section{YouTube}

Outside of the official Games Workshop web store, YouTube is the first avenue of MESBG content creation. YouTube plays the role of advertising and promoting continued global interest for the game. Independent from Games Workshop, YouTube Channels such as The Great British Hobby League [GBHL] organize videos that show painting tutorials, battle reports, documentation of tournaments, and general conversation about the hobby. The GBHL is the largest of the MESBG YouTube Channels, which represents 7,400 subscribers.

In connection with the global networking of MESBG, individuals from other countries and regions also create YouTube Channels that express interest in the game. From The Lotr SBG Team in North Carolina, and BlackFyre Productions in Ontario, Canada, to FTS Fellowship in Norway, players can see all aspects of the gaming world illustrated through YouTube. Furthermore, each YouTube Channel has a unique range of videos that address various aspects of the hobby (collecting, modeling, painting, playing, strategizing).

The majority of my informants expressed the fact that it was YouTube Channels that either provoked their interest in the game or pushed them to participate with the global gaming community. One MESBG player by the name of Frank, located in Syracuse, New York, and quite active in traveling across state borders for tournaments, said that if it were not for YouTube, he would not be as involved as he is in the various MESBG networks. While interviewing Frank in a hotel room at Nova Open 2018, he stated that he "would not have [participated in MESBG], nor would the American community have gotten so big if it were not for YouTube.” Frank, whose story correlates with many others, proceeded to say that he had collected the game miniatures since 2006 but never played until two years previous (2016) when he "stumbled" upon a GBHL YouTube video. After that, Frank viewed videos from the DCHL YouTube channel regularly that encouraged collection and attendance at tournaments. Frank then realized that there was a local community in his region that played the game. Since then, he has pushed himself heavily into the purchasing of models and competitive involvement in American tournaments.

It was through YouTube that Frank realized that "people actually play." Otherwise, he would have been just another collector of the consumer products. YouTube networked Frank into the world of MESBG where he is now part of its global association.

\section{Facebook}

Facebook functions as the second of the imagined spaces, and further functions as an avenue into the third (establishment). Facebook groups dedicated to the MESBG, like YouTube, are constructed to promote the hobby. Unlike YouTube, which primarily operates for the purpose of recruitment and entertainment, Facebook functions for participation and organization.

The American Strategy Battle Game Alliance [ASBGA] is an illustration of this function. The vast majority of both interviewees and those I met in participation at tournaments and for casual gaming are either associated with or part of the ASBGA Facebook group (740 members as of August 2018). The ASBGA Facebook group is essential to the American scene. It is where tournaments organize, and most interaction among the American community takes place .

On their page, the ASBGA Facebook group has files organized into sections that advertise upcoming events (tournaments) in the American region. Furthermore, one of the founders of the ASBGA created a Google Maps file where individuals reply to indicate their current place of habitation. They are then added as a pin to a Google map of North America (Picture 1). Through the process, all individuals from the group can see a virtual map of how close others are to themselves. An Atlanta, Georgia based player can see that there are others in Athens, Georgia. A Reading, 
Pennsylvania player sees that there are players in Lebanon, Pennsylvania and so on.

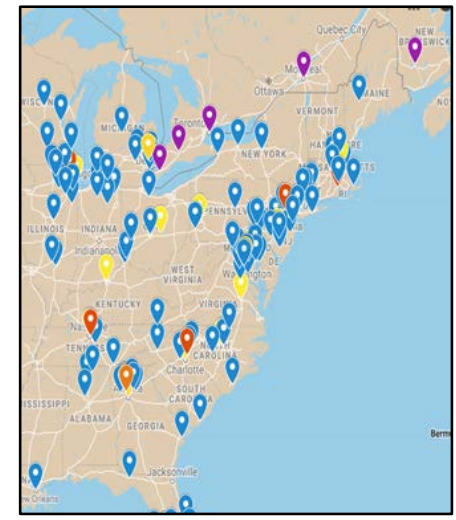

Picture 1 Google Map of Players

I used the ASBGA Google doc map as a reference for finding players in my proximity to establish local rapport, along with scheduling interviews. Many in the community use the ASBGA in order to network with local, national, and global MESBG players. In the process, a structured community of association develops by way of Facebook and is associated with Games Workshop products. From there, individuals are funneled back to YouTube for content creation. Furthermore, tournaments, which are vital events for the community, are both advertised and celebrated by Facebook groups. For example, current winners of competitions are named in the photo of the ASBGA group.

Participation in Facebook groups is essential to MESBG players as it is a place for expression of community values and social organization. Frank, whom I mentioned earlier, assured me in multiple interviews that social media (Facebook) is the core ingredient outside of YouTube for the MESBG community. His sentiments mirror my conversations with James. As a 53-year-old tournament organizer who has been active in the DCHL (District of Columbia Hobbit League) for multiple years, James asserts that social media is the primary reason that the game has survived for so long. In James' words, it is Facebook that is "completely responsible for its [MESBG] resurrection."

James went on to say that without Facebook, American MESBG players would be a sub-culture of individuals isolated from each other. Facebook, however, allows individuals to establish associations through organized groups. One only needs to join the ASBGA to know when and where upcoming tournaments will be held, as well as to find a place to have painting, list building, and other hobby specific conversations. James' comment on Facebook's role in the MESBG's revival was particularly true of the Tolkien inspired section of Games Workshop. James told me that it was the GBHL and DCHL who create a space on Facebook for players to organize, thereby demonstrating that the game is still alive and well on YouTube. This contributed to Games Workshop's current "resurrection" of model production and company-wide backing. In fact, I came to study MESBG at a vital time in its history with Games Workshop (2001-present). Through company-wide backing including scheduled releases spanning two years into the future, and new model manufacturing, the MESBG is right now going through a renaissance.

\section{Group Affiliation}

The second avenue of my ethnographic data collection relates to Arjun Appadurai's concept of "social neighborhoods." According to Appadurai, "neighborhoods, in this usage, are situated communities characterized by their actuality, whether spatial or virtual, in their potential for social reproduction" (Appadurai 1996, p.179). In most cases 'neighborhoods' are localities based in ethnoscapes, whether reproduced or made new (186). But culture can also function through social media, establishing 'virtual neighborhoods' of affiliation (195). As seen in my previous section, the MESBG community establishes itself through Facebook and YouTube, thus creating 'virtual neighborhoods' on social media platforms. Here we see the transfer of the MESBG locality from online networking to in-person participation.

I focus on three situations relating to social neighborhoods within the MESBG community. First, I illustrate how war-gaming stores offer members of many backgrounds a safe space to express themselves within an environment of acceptance. From there, I exhibit through a member of the Philly SBG [Philadelphia Strategy Battle Gamers] the meaning of community within MESBG association. Lastly, I show how individuals organize through regional affiliation as they come out of specific localities to also represent a broader association. I illustrate these situations with examples from my participation with East Pennsylvanian players in the Philly SBG (Philly Strategy Battle Gamers) group partnership.

\section{Local Stores}

Like a place of adoration, tabletop wargaming stores provide individuals with the icons, sacred space, and a congregation to pursue their specific way of cultural expression. Lined on each wall are products ranging from comic books, to board games, and to miniatures. 
Displayed within the store in glass cases are intricately painted armies distinct to different tabletop systems of play. Everything one needs to begin a journey towards a specific gaming system is advertised within the store, like a masterly crafted scheme that provides gamers with visual awe and a necessity to buy-a perfect capitalistic endeavor based on imagery that encourages wargamers to create large collections of miniatures, while also celebrating local player's position in the community.

In most cases, these stores have sections of two to eight $6 \times 4$ foot tables. Next to these tables are walls of various tabletop terrain (Picture 2). Wargamers can use the terrain to alter their customizable boards in whatever way they seek. Dungeons and Dragons participants use tables for their journeys. MESBG players recreate their two player, turn-based, pointsmatched Middle-Earth battles, and Warhammer 40Kers establish planetary systems of conflict. The sky is the limit for envisioning other worlds as game stores provide a place where individuals can transfer themselves into any historical era, or fantasy world, and escape for a few hours from the complexities of everyday life.

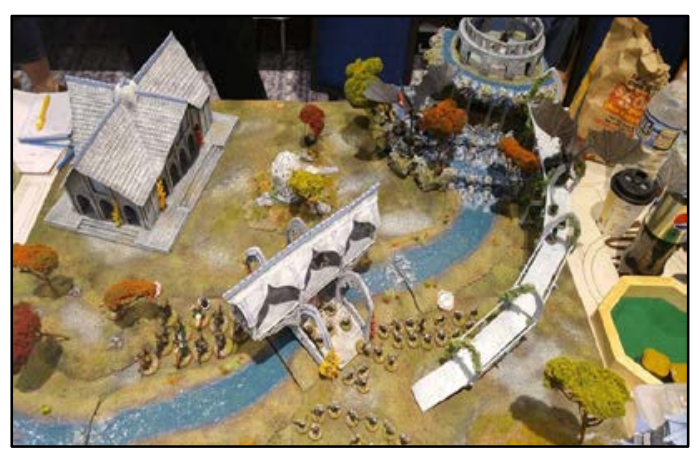

Picture 2

\section{Tabletop Terrain}

Between two and three gamers might show up on weekdays to fit games into their working-class lives, while weekends feature crowded tournaments. Every night of the week has packed stores with gamers at play. Game stores, in that sense, are places where the tabletop wargaming culture can literarily play out. One only has to bring dice, rules, measuring tools, and miniatures (Pictures 3 and 4).

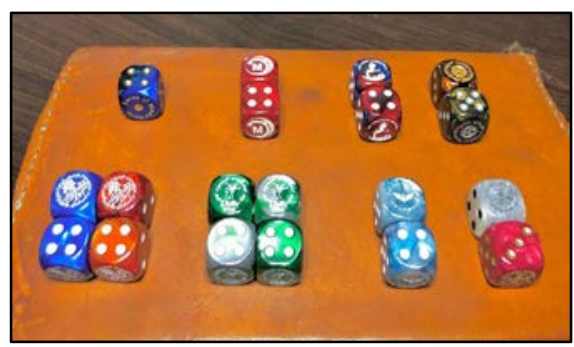

Picture 3

Dice Representing Various Groups

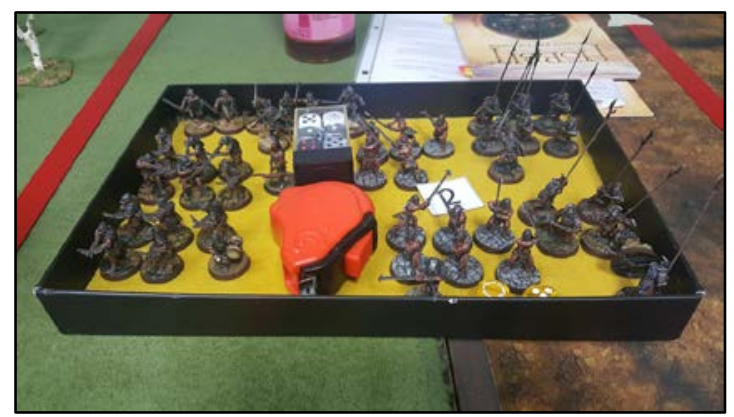

Picture 4

Miniatures Displayed

To members of the MESBG community, gaming stores are a social neighborhood and an extension of their imagined space already experienced through social media. Thus, for the MESBG association, local stores function as part of the mosaic of the MESBG sub-culture. YouTube piques individual interest. Facebook funnels individuals into participation. Then the gaming store operates as a physical place where one can foster a sense of establishment. I categorize gaming stores as social neighborhoods of the MESBG community because they are offshoots of an identity based in imagined spaces on social media.

\section{Voices From the Philly SBG}

As stated previously, the most common physical establishments where MESBG communities play are at local gaming stores (the game is also played in individuals' homes). For players, local gaming stores offer a secure area where they can express themselves without risking judgment. Stores allow a safe space to both organize small tournaments and interact with one another in casual conversations. I apply the term "safe space" as a place intended to be free of bias, where one's physical or social standing is not judged. My countless hours of participation-observation in gaming stores demonstrate, in multiple ways, that stores are indeed a safe space. One of my primary informants, whom I will call Murphy, confirmed this reality. 
During the period of my data collection, I drove bimonthly to the outskirts of Philadelphia where I picked Murphy up from his house and proceeded to the local gaming store to play the MESBG. Murphy appears outwardly shy and reluctant to take up life responsibilities. Nevertheless, in spite of the social anxiety he expresses in other contexts, when Murphy walks into wargaming stores (especially the one he works in), he becomes a new person. Confidence and assertiveness overcome a body language that is usually passive and uncertain. Murphy instantly becomes part of an association of tabletop wargamers as he fits directly into his tribe.

Murphy always chats with other wargamers. Conversations between Murphy and others highlight the communal atmosphere of game stores as a social neighborhood. Phrases such as, "what are you playing?" "Ah, I used to play Warmachine but stopped when they changed the rule set." Or, "LOTR, I have not seen that game played since 2010." Such chatter illustrates the connection between gamers across multiple systems. Furthermore, regardless of coming from different walks of life, wargamers find harmony in their common interests. Murphy affirms this when he states, "no one cares when the dice hit the table."

Murphy's statement, "no one cares when the dice hit the table," refers to the fact that in the war-gaming sub-culture members disregard each other's religion, social class, ethnicity, or sexual orientation. In my time observing tabletop stores' relationship to the MESBG community, I participated with individuals with lifestyles ranging from nurses, to graduate students, to retail managers, and to independent business owners.

There is, however, a distinctively masculine orientation to the gaming community. Coded in the language of MESBG association lies a sub-culture that sometimes has aggressive connotations. Phrases such as "I wrecked them," "I made my opponent my bitch," or "my forces raped theirs" show the masculine undertones in the language of tabletop wargamers. Although females are outwardly welcomed (wives and girlfriends, who seldom participate in the tournaments), it cannot be denied that the community is associated with a kind of hyper-masculinity. Affiliation is through males whose language reflects aggression based in warfare and domination. Other wargaming systems produce parallel social environments.

Still, the connections established are not restricted to gaming spaces. It is not rare to see MESBG friendships transfer into other parts of participants' lives. 'SBG buddies' attend weddings, help each other move to other states, and support one another through deaths in the family. Murphy exemplified this in one of our conversations when he told me that doctors had found a cancerous tumor in the throat of a wargamer by the name of Bill who frequents his store. Murphy expressed optimism regarding his friend's situation when he stated, "that fucker always rolls high in our games ... he will do the same with his cancer."

Bill did end up "rolling high" as he survived the ordeal. Bill's lucky dice rolls were not the reason he "won the war against cancer," but the support he received from his wargaming community demonstrates that the friendships established in playing games such as the MESBG transfer not only across fantasy tables but also into personal lives. The social networks formed through MESBG affiliation are not merely recreational. They also benefit participants in times of distress and need.

On the whole, MESBG. though not without its social conflict, constructs an association based on acceptance. In Murphy's straightforward language, he has "yet to meet an asshole" who plays the game. This sentiment was echoed in multiple conversations with other members who always refer to "the community" of MESBG as a place of open arms, where all are accepted into the fold.

Community is one hundred percent of my love for the game. I have yet to meet an asshole who plays SBG ... No one cares when dice hit the table ... We have so much to talk about instead of divisions, like Tolkien's lore and the movie. I love it all.

\section{Group Affiliation}

The MESBG community exemplifies Arjun Appadurai's concept of social neighborhoods, both virtually through Facebook, and in-person by way of local gaming stores. The MESBG affiliation further develops an "imagined space" created from J.R.R. Tolkien's Middle-Earth (2014), and encouraged by Games Workshop's miniature production.

Groups create logos themed with Middle-Earth inspired imagery and their place or region. These logos are then reproduced on dice (with the logo replacing the six on a six-faced die), shirts, and other memorabilia. Pictured below is an example (Picture 5). The dice depicted belong to the Philly SBG group. One can see on the dice Smaug the dragon wrapped around the Philadelphia Liberty Bell with the 'One Ring to Rule Them All' inscription surrounding the logo (Picture \#5).The green and gray color scheme represents Philadelphia's regional NFL team (The Eagles). 


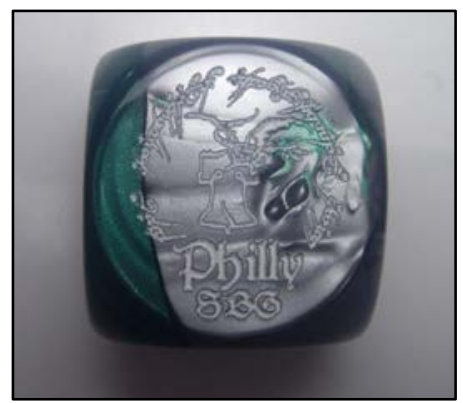

Picture 5

Philadelphia SBG Dice

Philly SBG is not the only group that creates their own logo for dice. Ontario based players have red and white dice with Tolkien inspired imagery encompassing a maple leaf. Scottish players customize dice with the Rampant Lion, and English groups have similar dice representing their region. These memorabilia are found in every MESBG group, and demonstrate pride in specific geographic locations while reproducing Tolkien animated lore. Below is a photo of a group logo positioned on a shirt which a member commonly wears when attending/hosting tournaments. (Picture \#6)

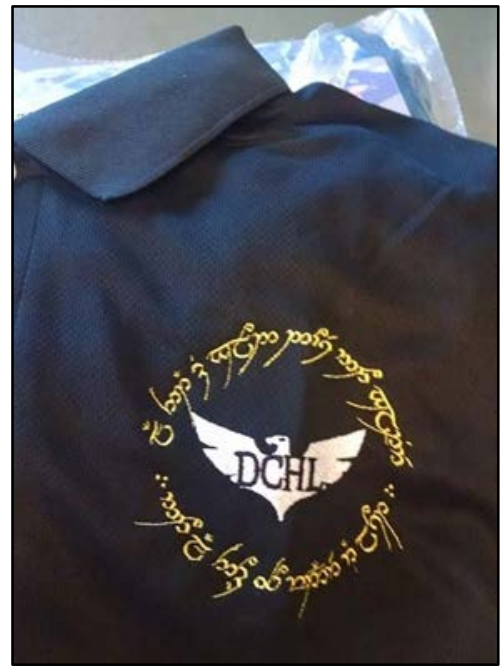

Picture 6

Group Logo on Shirt

The visual representation of group affiliations also spreads across global communities of the MESBG. For example, in individual games at competitions, players participate in swapping dice as a sign of respect between opponents. When trading miniatures on Facebook groups, dice might also be exchanged as individuals collect them to show their participation in the global community of MESBG. It is not rare to play a member, either at a local gaming store or tournament, using dice that represent MESBG social neighborhoods around the world.

\section{The Tournament Scene}

My Throne of Skulls pilgrimage has been typical of my other Warhammer World trips. One of the advantages of having been able to make this journey more than once. The twelve hour plus plane flights and a two hour train trip followed by a very short taxi drive. A meal and then bed.

Waking up in the middle of the night because my body clock is still eight time zones away. So my day starts with an early breakfast and then to twiddle my thumbs while I wait for Warhammer World to open. Which at the time I write this is still two and a half hours away.

While age and familiarity have toned down the anxiety, excitement and anticipation of the weekend before me, I still feel like a kid standing outside Disneyland waiting on the gates to open.

I still have not checked to see how well my miniatures travelled. Typically there is one or two that require some repair or attention.

So in the meantime I sit here writing up army lists in my head and of course they are for armies I have not painted yet.

Just like sagas, individuals document through Facebook and YouTube their experiences journeying to compete and celebrate their place in the global family of MESBG. By going to tournaments, participants accumulate social capital, of which a "thick description" reveals deeper and deeper layers of meaning (Geertz 1973: 10).

I will describe below three aspects of these competitions that make an association with the MESBG meaningful. First, I will center my narrative on the structure of tournaments, and the role Tournament Organizers [TOs] have in the process. Second, I will analyze the significance of traveling distances for participation in the MESBG community. I focus this section on the role that a tournament plays in the MESBG sub-culture as a form of pilgrimage. Last, I will describe how social capital is accumulated, creating a hierarchical standing of individuals despite the fact that the competition is yet viewed as taking place within a community of acceptance.

\footnotetext{
A California based player posting on the ASBGA Facebook group page about his "pilgrimage" to attend a MESBG tournament in
} the United Kingdom. 


\section{Structure and Organization}

Tournaments are the height of a war gamer's experience with their hobby. MESBG tournaments differ in size. A Northern Virginia tournament (Fords of Potomac) might attract around 16-24 participants from the surrounding states, while competitions in North Carolina (The Ring Goes South) have similar numbers. When it comes to the American scene, small tournaments are one-day events based out of local gaming stores. Large ones are grander war-gaming conventions in hotel lobbies.

One-day tournaments usually consist of three to four games where those with the highest scorings place 1st, 2nd, and 3rd. Larger tournaments are conducted over the span of multiple days (usually Friday to Sunday), and will have other events such as painting competitions, doubles (teams of two), and more casual type scenarios. While small gatherings are regional (Picture 7), large tournaments obtain national and even global attention. For example, the largest MESBG tournament in North America (Nova Open) had 75 participants in 2018, which included Canadian, American, Polish, and British nationals. Prizes are common at tournaments and usually consist of MiddleEarth inspired collector items. Awards differ in price range, depending on the size of the tournament.

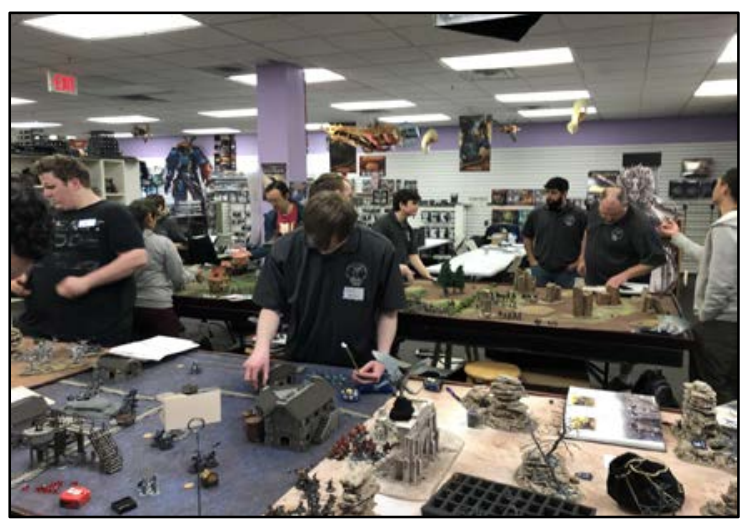

Picture 7

\section{The Game in Action: A Regional Tournament}

The life blood of tournaments is in both those who travel long distances to attend and in the organizers. Tournament Organizers function as guardians to the community who establish themselves as figures of authority. Without TOs to set up the larger structured tournaments, the MESBG association would be confined to local gaming and online interaction.

TOs are established members of the MESBG subculture, and have experience attending multiple tournaments. They also are highly esteemed in their local gaming community. One has to accumulate themed
$4 \times 4 \mathrm{ft}$ boards, have an organizational personality, and the social capital to get participants from other states to attend your tournament. Their primary purpose is to form systems of exchange between players that parallel those described by French sociologist Marcel Mauss in his book titled, The Gift (2000). Thus, players based in Connecticut, North Carolina, Philadelphia, Maryland, or Chicago have social obligations to attend each others' tournaments.

According to Mauss, society has formed systems of gift exchange based on obligation. By analyzing the Maori word taonga's 'impelled' and 'obliged' meanings, Mauss suggests that society naturally establishes systems of bilateral participation (Mauss 2000: 11). Mauss concludes that it is "the 'basic imperialism' of human beings" to form systems of obligation (Mauss 2000: 65). Such systems of obligation can be found throughout culture as societies build networks. In the process, they establish relationships based on mutual commitment.

TOs have a special role in constructing systems of mutual obligation in the MESBG community, and thus contribute to its specific style of cultural formation. For example, when a New Jersey group presents a tournament attended by East Pennsylvanian participants, it is then the obligation of the Pennsylvanian based group to perform a competition for the New Jersey players to frequent. The same commitment goes for Georgia and North Carolina based affiliations, and so forth.

Prizes at tournaments are reminiscent of the potlatch of the Pacific Northwest described by Mauss. Regional groups who organize tournaments try to outpace other groups in the size of the prizes they present, thereby producing social prestige for the group. Much like the potlatch's gift economy, TOs sacrifice an unsustainable amount of personal resources in order to achieve social influence for themselves and the regional group they represent. The accumulation of social capital encourages individuals to introduce new competitions throughout the year.

Thus, the tournaments create relationships of exchange that are cemented by obligation and produce social capital. In Mauss' words, "all in all, it is mechanisms of obligation, and even obligation through things, that are called into play" (Mauss 2000: 23). In fact, "generosity is obligation," says Mauss (18). That "generosity" is essential for the continuation of the MESBG's sub-culture.

\section{Pilgrimage}

Like a religious pilgrimage, tournaments are a "rite de passage" for anyone in the gaming community. Individuals can, through the process of attending tournaments, hone their skills in the game and achieve social prestige through finding their place in the 
competitive scene. Victor and Edith Turner's Image and Pilgrimage in Christian Culture (2011) offers insight into the process.

The Turners studied the complex notion of a pilgrimage within Mexican, Marian, and Medieval contexts. In their study of the deep ancient symbolism involved, they identified three phases of a pilgrimage: separation, limen, and aggregation (Turners 2011: 2). On the pilgrimage, individuals separate themselves from ordinary life and transcend to a liminal phase. They then cumulate their experience by an aggregation back into society. Then "like all sustained mass movements, pilgrimages tend to accrete rich superstructures of legend, myth, folklore, and literature" (Turners 2011: 23).

With months of financial planning, MESBG participants travel long distances for their hobby. They thus separate themselves from everyday life and enter into the world of the MESBG. Once in the tournament, participants transcend into a liminal phase in which they play for prestige, not knowing their rankings until the process concludes and rankings are put up. The conclusion of this phase is when tournament standings are read out loud and later posted on the ASBGA Facebook page (aggregation) and the participants return home.

Tournament experiences are reproduced in the MESBG subculture through YouTube videos and Facebook posts as individuals transform into legends around the community. Through the process, games form local myths and sagas about specific happenings. Every individual of the MESBG association who has attended a tournament has an event immortalized in his or her participation. Players bring up stories about the time they rolled well, or when they needed one dice roll out of twenty to be a six and they failed to produce any. The creation of such lore is an important reason why MESBG participants put an enormous effort into attending tournaments.

\section{Social Hierarchies}

The tournament scene functions for the MESBG community as a hierarchical formation of social prestige and capital. Those on top-table have higher rank than other players. Top-table refers to those who place high in final tournament scorings. Skill in the game, however, is not the only way the community recognizes individuals in tournaments, as competitive painting and sportsmanship also are valued, reflecting other aspects of the hobby. The vast majority of those interviewed asserted that the competitive nature of the game is second to the social function of the MESBG association. Still, my informants' eyes lit up with the idea of winning or placing first, second, or third in a tournament. Frank's experience illustrates this covert enthusiasm for winning .

Frank, an Upstate New York-based player, considers himself competitive, but dismisses the notion of playing to win. Instead, Frank downplays his skill by assuming top-table players (those who place high in standings) to be "cutthroats" because they take "nasty lists." "Nasty lists" refers to the army list building process of the game. Many assume that those in high rankings of tournaments have a skill not only with strategy but also with abusing the matrix of a "point matched game" to take advantage of every small thing that would influence specific in-game situations. Many players ask about tournament winner's lists. The prestige of winning not only produces trophies and prizes. On Facebook and YouTube winners are praised and talked about for months to come.

Most of my conversations with Frank over Facebook Messenger centered on who plays what, and competitive list building. Frank affirms the importance of knowing how to build specific lists because the MESBG meta ["most effective tactics available"] is constantly changing. In Frank's words, "the meta always changes and you have to be on top of it . . I like knowing what people bring on top-table because it helps [me] know what [is] current[ly] [competitive]." Toptable player's lists establish what is competitive in the tournament scene. Current MESBG meta, therefore, is directly influenced by players who win games, demonstrating how influential tournament winners are in the overall sub-culture.

The social prestige obtained in tournaments demonstrates that there is a hierarchy in which individuals find glory as top-table players who are both respected and feared. Yet notions of belonging to the group still prevail. The ranking system at tournaments gives individuals a position in the MESBG community. One knows where they stand when they attend gatherings. If you are competitive, you achieve social prestige with other 'cutthroats.' If you enjoy painting and terrain building over competitive-play, your talents will be admired by many. Furthermore, if you are neither strategic nor a good painter, you can still find honor as many tournaments show support for participation through specialized prizes for sportsmanship.

\section{Anthropological Analysis}

The MESBG sub-culture expresses itself transnationally through modern technology, as their "imagined space" of affiliation is based on social media platforms. The term comes from Edward Said's Orientalism, in which Said described imagined spaces as Eurocentric depictions of the Orient found in literature, art, and elsewhere (1979). 
Said's work has demonstrated the significance of imagined spaces for culture, and is especially relevant to post-modern societies such as the MESBG subculture. The MESBG community is based on an imagined space of romanticized impressions of Tolkien's world in The Lord of the Rings. Individuals escape into a socially constructed world that has no real physical reality, but instead has a virtual one based on online and in store creations. The latest technological advances play an important role in the creation of this world.

Arjun Appadurai's Modernity at Large also addresses the phenomenon of imagined worlds. According to Appadurai, "we live in a world of many kinds of realism, some magical, some socialist, some capitalist, and some that are yet to be named" (Appadurai 1996: 53). In post-modern times, our understanding of culture has changed. Mass communication through online networking is a prime reason. Cultures "yet to be named" such as the MESBG association, base themselves on a social imagination produced through media platforms.

Appadurai's best known theorizing is his notion of "scapes" (Appadurai 1996: 33). Like landscapes, the "scapes" are global formations of culture flow, including ethnoscapes, technoscapes, financescapes, mediascapes and ideoscapes. The MESBG constructs a world of ideas, beliefs, and values, (ideoscape), expressed through social media platforms (mediascape), and performed in tournaments (technoscape). Through financial exchanges on eBay and Facebook trade groups, the sub-culture also engages in economic transactions (financescape).

It is essential to understand these virtual social realities in order to formulate an anthropology that can account for the current globalized world in which individuals can form identity, community, and culture through a tabletop fantasy game. Appadurai comments, "ethnography must redefine itself as that practice of representation that illuminates the power of large-scale, imagined life" (Appadurai 1996: 55). Theorizing tabletop wargaming through the lens of Appadurai's work provides us with a deeper understanding of how culture in the 21st century is established through the social imagination.

As mentioned above, Victor and Edith Turner's work on pilgrimages is helpful for understanding the role of tournaments as instrumental formations of the MESBG community. Tournaments establish superstructures of legends, myths, and literature. When analyzing war gamers participation in tournaments, the individual's role is parallel to a pilgrim journeying to both celebrate and commemorate their sub-cultural affiliation. Local groups also collaborate as multiple members converge in one place to achieve communal bonding and personal prestige. Concepts such as pilgrimage are essential to anthropological discourse concerning developing Western patterns of cultural practice. Though to many Westerners pilgrimage is an ancient idea with historical ties to Christianity, my study of the MESBG community shows that Westerners can repackage the concept in new forms, creating new traditions that fulfill individual's yearning for fellowship and identity.

My ethnographic research on community, identity, and social mobilization among MESBG participants illustrates an essential shift in contemporary anthropology's perception of culture. No longer are ethnographers confined to studying non-Western societies in isolated localities. Instead, with the advent of modern technological advances, culture is constructed via global networks.

My research further shows how Western cultural formations adapt to post-modern circumstances. Social media offers individuals the tools to socialize across ethnic, class, and national barriers. Fantasy tabletop wargaming is not an obstacle to individuals of different backgrounds. Rather, it is an open door to a common identity, cultural expression, and global affiliation through an escape into another world.

The MESBG world is as fictional as The Orient, a construct that people imagine through various "scapes." Social media and tournaments reinforce shared beliefs in this global virtual community. Through participation, individuals find safe spaces where they can escape into a world of acceptance and belonging. A "thick description" of Middle-Earth Strategy Battle Gamers illustrates that their social system is more than just mutual exchange by way of tabletop wargaming. The MESBG global association is a sub-culture with hierarchies, distinct organization, and wargaming traditions.

Thus, this research reveals hidden experiences of the West that describe the changing face of cultural participation. The field of anthropology can only understand these social formations if we expand our presence to new frontiers of information gathering, such as the internet. Establishing an anthropological presence online, while still using conventional data collection methods, not only opens the door to unknown cultures of the West, but also reveals political, social, and neo-nationalist movements in action as online exchange formulates new avenues of identity expression.

\section{Theological Implications}

Theology and anthropology are both concerned with the question of how to benefit of humanity through their quest to understand it. Anthropology strives to document human experience through social scientific lenses, while theology seeks to describe the nature of humanity's participation in and relationship to God. 
This ethnography demonstrates that human beings seek to find acceptance through communal interaction. Tabletop wargaming neighborhoods organize safe spaces where individuals can find acceptance through cultural exchange. Despite the competitive struggle exhibited within the MESBG hierarchy, members create an atmosphere of openness. Like a religion, the sub-culture creates a meaningful world for its members that includes a kind of interactional fellowship.

Christians, like anthropologists, must adapt to the changing face of cultural participation when considering their ministry. Theologians offer insight into this new situation. Craig Ott, Stephan J. Strauss, and Timothy C. Tennent, in their book, Encountering Theology of Mission, stress the importance of sending in Christian mission. According to Ott, Strauss, and Tennent, sending missionaries into hidden sub-groups is central to Christianity's purpose (2010: 74). Christianity is a missionary religion that transcends culture, ethnicity, and class as it spreads throughout the world.

The harvest is plentiful, but the laborers few. (Luke 10:2 NIV)

Likewise, David Bosch, in Transforming Mission, (1991) concludes that there are hidden communities across society that may be isolated from God's universal call to reconcile with Himself. Bosch reminds us that every social environment is a mission field for Christians (1991: 370, 379, 380). Part of the message of my ethnography is that Western tabletop wargamers are among those who are isolated from Christianity. The contextualization of the Gospel into these groups is, therefore, essential to fulfilling Christ's mandate to "make disciples of all nations" (Matt 20:19).

Stephen B. Bevans, in his book, Models of Contextual Theology (2013), demonstrates how Christianity is placed within cultural worldviews and practices. According to Bevans, Christian theology is unique in that it draws from three sources, "scripture, tradition, and current human experience" (2013: 4). The divine mission was always contextualized within cultures, providing a model that Christians must continue to follow. Old Testament scripture was rooted in ancient traditions specific to the cultures of the time, as the Hebrew God presented Himself to a nomadic Semitic society. Christianity emerged when Jesus came to the Jewish people at the height of the Roman occupation under Hellenic influence. Jesus' ministry crossed multiple cultures and human experiences. Upon Jesus' death, His disciples spread the Gospel across the Mediterranean region, and then to "the ends of the earth" (Acts 1:8). Thus began a tradition of infusing cultures with the Christian message.

Infusion and exchange have always been themes in the historical Christian paradigm. Within the many tribes, nations, and tongues, Christianity penetrates every socio-economic group. Christ calls his followers not only to spread His love to the ends of the earth but also to the hidden cultures that are found adjacent to ordinary societal activities.

The apostle Paul stated, "To the weak, I became weak, to win the weak. I have become all things to all people so that by all possible means I might save some" (1 Corinthians 9:22, NIV). I am not suggesting that the Gospel needs to morph its theological language into that of the tabletop wargaming culture. Christians are not required to re-word scripture into an NTWV (New Tabletop Wargaming Version) Bible. Instead, I argue that as Christians, we should learn the cultural language and environment of each community to which we belong. From that position, we can translate the love and acceptance of our God into terms that can be understood and accepted..

As anthropologists, we endeavor to view the world through the eyes of those we document. As Christians, we try to be relevant in the post-modern world and to adapt to unfamiliar affiliations. By reimagining the contemporary nature of social participation, we can contextualize Christ's message of hope, love, and inclusion into the cultural language of not only tabletop wargamers, but every sub-cultural formation in obedience to Christ's command to, "Therefore go and make disciples of all nations, baptizing them in the name of the Father and of the Son and of the Holy Spirit, and teaching them to obey everything I have commanded you. And surely I am with you always, to the very end of the age" (Matthew 20:19-20, NIV).

\section{References}

Appadurai, Arjun. 1996. Modernity at Large: Cultural Dimensions of Globalization. Minneapolis, MN: Univ. of Minnesota Press.

Bevans, Stephen B. 2013. Models of Contextual Theology. Maryknoll, NY: Orbis Books.

Bosch, David J. 1991. Transforming Mission. Maryknoll, NY.: Orbis Books.

Eisenhowser, Dwight. 1944. Order of the Day, 6 June 1944. http://universityarchives.com/Dwight_Eisenhower -ITEM65997.aspx

Geertz, Clifford. 1973. The Interpretation of Cultures. New York: Basic Books.

Mauss, Marcel. 2000. The Gift: Forms and Functions of Exchange in Archaic Societies. NY: W.W. Norton. 
Ott, Craig, Stephen J. Strauss, and Timothy C.

Tennent. 2010. Encountering Theology of Mission: Biblical Foundations, Historical Developments, and Contemporary Issues. Grand Rapids, MI: Baker Academic.

Said, Edward W. 1979. Orientalism. NY: Vintage.

Tolkien, J. R. R. 2014. The Lord of the Rings. London: HarperCollins Publishers.

Turner, Victor Witter, and Edith L. B. Turner. 2011. Image and Pilgrimage in Christian Culture. New York: Columbia University Press.

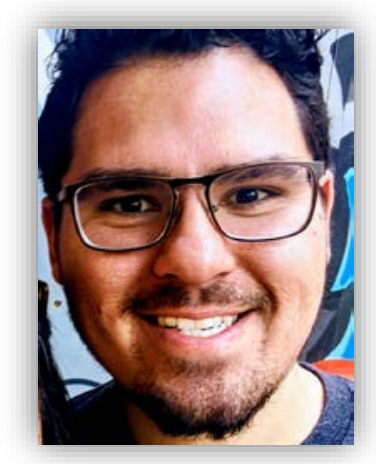

Rainier Lee is a graduate of the MA in Theological and Cultural Anthropology at Eastern University. He has research interests in social media's effect on culture, specifically how communities organize within its platforms. Rainier also enjoys studying British colonial history and current political movements.

Author email: rainier.lee@eastern.edu 